\title{
Tudi navadni bršljan lahko zboli: vzroki poškodb listov navadnega bršljana v drevesnici Rimš v letu 2012
}

\section{Nikica OGRIS*}

Pri zdravstvenem pregledu drevesnice Rimš v letu 2012 smo na navadnem bršljanu (Hedera helix L.) opazili obsežne poškodbe listov (slika 1), ki sta jih povzročali dve bolezni, tj. bršljanova rjava listna pegavost in bršljanov ožig. Bršljanovo rjavo listno pegavost povzroča gliva Colletotrichum trichellum (Fr.) Duke (1928), sinonim Vermicularia trichella Fr. (1828). Bršljanov ožig povzroča Alternaria hederae (J.V. Almeida \& Sousa da Câmara) P. Joly (1964), sinonim Macrosporium hederae J.V. Almeida \& Sousa da Câmara (1903).

Gliva Colletotrichum trichellum je zelo pogost parazit listja navadnega bršljana, ki je razširjena po vsej Evropi in Aziji (Duke, 1928; Brandenburger, 1985; Ellis M.B. in Ellis J.P., 1985). Kuži lahko liste, peclje in stebla, ki imajo poškodbe - rane. Zlasti povzroča bolezen na potaknjencih in osebkih, ki se razraščajo po tleh. Prijajo ji namreč vlažne razmere. Acervuli (nespolna trosišča) se razvijejo na nekrozah in so rjavi do črni, mlajši so svetlejši, premera do $270 \mu \mathrm{m}$ (slika 2 in 3 ). Prezimuje v obliki sklerocija (gost preplet hif z vključenimi delci gostiteljskega tkiva; Batič in sod. 2011) na odmrlem delu lista ali peclja. Ob vlažnem vremenu lahko na acervulih opazimo svetlorumene kapljice, v katerih je ogromna količina nespolnih trosov - konidijev. Konidiji so brezbarvni, vretenasti, ravni ali rahlo ukrivljeni, $\mathrm{z}$ eno ali več oljnimi kapljicami, velikosti 15-28 × 3-5 $\mu \mathrm{m}$ (slika 4; Duke, 1928). Teleomorf (spolna oblika) glive ni poznana, domnevajo pa, da pripada rodu Glomerella Spauld. \& H. Schrenk (1903). Konidiji se širijo s pomočjo tekoče vode in dežnih kapljic, prenašajo jih lahko tudi žuželke. V ugodnih vremenskih razmerah kalijo zelo hitro, že v 18. urah (Duke, 1928). Gliva Colletotrichum trichellum povzroča nekrozo listov navadnega bršljana. Te so temno rjave s svetlejšim osrednjim delom, oblika nekroze je skoraj pravilno okrogla, od zdravega tkiva je jasno ločena z odebeljeno mejno črto; rjave pege so različne velikosti in neenakomerno razporejene po listu in peclju (Lohrer, 2011). Nekatere pege lahko izpadejo in list zato izgleda kot prestreljen, luknjičav. V ugodnih ekoloških razmerah je širjenje nekroze hitro in lahko obsega večji del ali celo površino lista ali se celo širi $\mathrm{v}$ pecelj in v steblo.

Zanimivo je, da je bila gliva Colletotrichum trichellum v Združenih državah Amerike in v Kanadi pravno regulirana in so jo obravnavali kot karantensko glivo. Fitosanitarna inšpekcija jo je večkrat prestregla v ZDA pri uvozu navadnega bršljana iz Nemčije in Irske v letu 1951, ponovno iz Nemčije v letu 1956 in iz Italije v 1957 (Hunt, 1952, 1957, 1958). V Kanadi so jo prestregli v Britanski Kolumbiji dva krat v letu 1964 pri uvozu navadnega bršljana iz Evrope, severne Afrike in zahodne Azije (Ginns, 1986).
Bršljanov ožig, ki ga povzroča gliva Alternaria hederae, prepoznamo po nekrozah nepravilne oblike na listih , ki so temno sive do črne barve. Je šibek parazit in saprofit, pogosto se pojavlja na osebkih, ki so pod stresom, kot so suša in vročina. Konidiji se razvijajo na posebej oblikovanih hifah, t.i. trosonoscih (konidiforih); s prostim očesom jih opazimo kot temnosiv do temnorjav mokast poprh, ki se pojavlja na odmrlem delu lista (slika 5). Konidiji so v obliki kija, pogostokrat se razvrščajo eden za drugim v verigah, so kostanjevo rjavi, imajo 4-5 prečnih in 1-3 podolžnih sept, veliki 26-33 × 11-13 $\mu \mathrm{m}$ (slika 6). Glivo Alternaria hederae ne moremo ločiti od drugih vrst iz rodu Alternaria, ki imajo majhne trose (Simmons, 2007). O biologiji in ekologiji glive Alternaria hederae je malo znanega. Po naših opažanjih se bolezen pogosteje pojavlja na potaknjencih in osebkih, ki imajo liste bližje tlom. Teleomorf ni znan, najverjetneje pripada rodu Clathrospora Rabenh. (1857) ali Leptosphaeria Ces. \& De Not. (1863).

\section{Ukrepi}

Okužene rastline odstranimo in uničimo, kajti s tem zmanjšamo infekcijski potencial zajedalskih gliv. Jakost okužbe je tesno povezana s povečano vlažnostjo (Lohrer, 2011). Zato poskrbimo, da je med osebki dovolj prostora (zračnost), na nadzemnih delih se ne sme zadrževati voda, do večernih ur se mora listje posušiti. Zvečer jih ne smemo zalivati. Pred širjenjem bolezni v drevesnicah bršljan zaščitimo s fungicidi, ki vsebujejo eno od naslednjih aktivnih snovi: tebuconazole, trifloxystrobin, azoxystrobin, metiram, myclobutanil (Lohrer, 2011; Surviliene in Dambrauskiene, 2006). Škropimo vsakih 14 dni.

\section{Možnosti zamenjave}

Bršljanovo rjavo listno pegavost lahko zamenjamo z bršljanovim bakterijskim ožigom, ki ga povzroča bakterija Xanthomonas campestris pv. hederae (Sinclair in sod., 1989). Omenjena bakterija poškoduje bršljanove liste, razvijejo se rjave pege brez jasne meje med obolelim in zdravim delom lista; robni del nekroze je videti moker in nasičen $z$ vodo. Simptom poškodb zaradi glive Colletotrichum trichellum so prav tako rjave pege različnih velikosti, vendar imajo temno rjav in jasno ločen rob od zdravega tkiva.

Glivo Alternaria hederae je izjemno težko razlikovati od drugih vrst iz rodu Alternaria, saj rod Alternaria vključuje več kot 1000 vrst in je mnoge med njimi možno ločiti le na podlagi molekularnih analiz (Simmons, 2007).

Opomba: vzorca obeh gliv sta shranjena v Mikoteki in herbariju Gozdarskega inštituta Slovenije, Colletotrichum trichellum št. LJF 3363, Alternaria hederae št. LJF 3364. 


\section{Viri}

Batič F., Košmrlj - Levanič B., Martinčič A., Cimerman A., Turk B., Gogala N., Seliškar A., Šercelj A., Kosi G. 2011. Botanični terminološki slovar. Ljubljana, Založba ZRC, ZRC SAZU: 650 str.

Brandenburger W. 1985. Parasitische Pilze an Gefäßpflanzen in Europa. Stuttgart, Germany, Gustav Fischer Verlag: 1248 str.

Buller A.H.R. 1958. Researches on fungi, Volume IV: further observations on the coprini together with some investigations on social organisation and sex in the Hymenomycetes. New York, Hafner Publishing Co.: 329 str.

Duke M.M. 1928. The genera Vermicularia Fr. and Colletotrichm Cda. Transactions of the British Mycological Society, 13, 1-4: 156-184

Ellis M.B., Ellis J.P. 1985. Microfungi on land plants: and identification handbook. Sydney, Australia, Croom Helm: 818 str.

Ginns J. H. 1986. Compendium of plant disease and decay fungi in Canada 1960-1980. Ottawa, Research Branch, Agriculture Canada: 416 str.

Hunt J. 1952, 1957, 1958. List of intercepted plant pests: 1951, 1956, 1957. Washington, D.C., United States Department of Agriculture, Plant Quarantine and Control Administration
Lohrer T. 2011. Pilzliche Blattflecken an Efeu. ARBOFUX - Diagnosedatenbank für Gehölze. http://www.arbofux.de/pilzlicheblattflecken-an-efeu.html (19. 11. 2013)

Simmons E. G. 2007. Alternaria: an identification manual. CBS Biodiversity Series No. 6, CBS Fungal Biodiversity Centre, Utrecht, Netherlands, 775 str.

Sinclair W.A., Lyon H.H., Johnson W.T. 1989. Diseases of trees and shrubs. Comstock Publishing Associates, a division of Cornell University Press: 512 str.

Surviliene E., Dambrauskiene E. 2006. Effect of different active ingredients of fungicides on Alternaria spp. growth in vitro. Agronomy Research, 4: 403-406

*Gozdarski inštitut Slovenije, Večna pot 2, 1000 Ljubljana nikica.ogris@gozdis.si

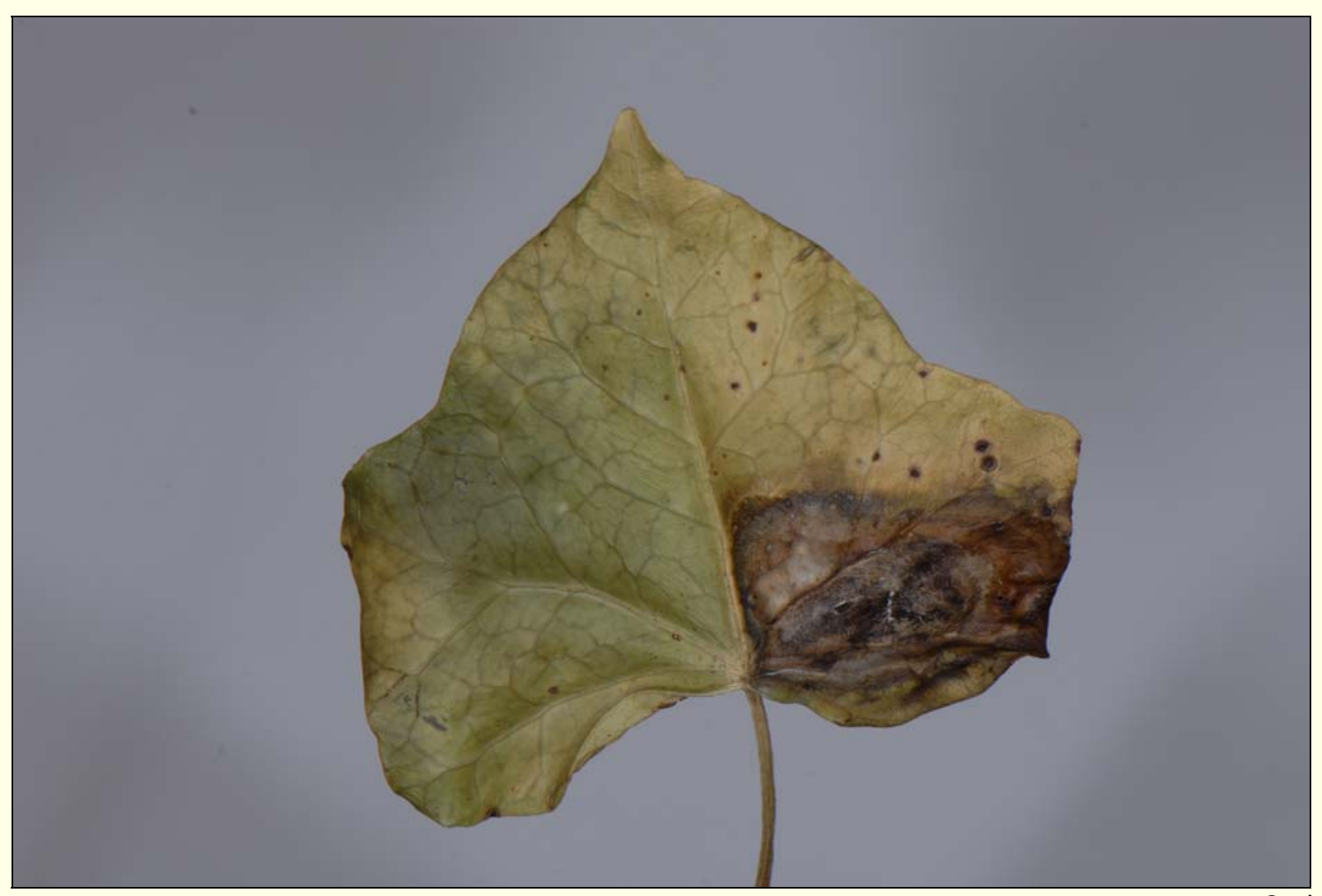

Slika 1: List navadnega bršljana sta poškodovali dve bolezni: bršljanova rjava listna pegavost in bršljanov ožig (Foto: N. Ogris)

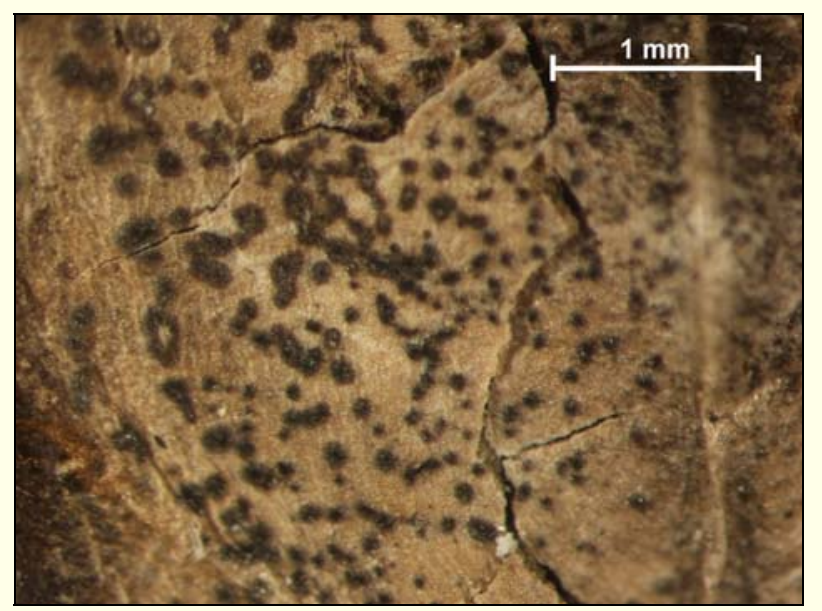

Slika 2: Acervuli glive Colletotrichum trichellum (Foto: N. 


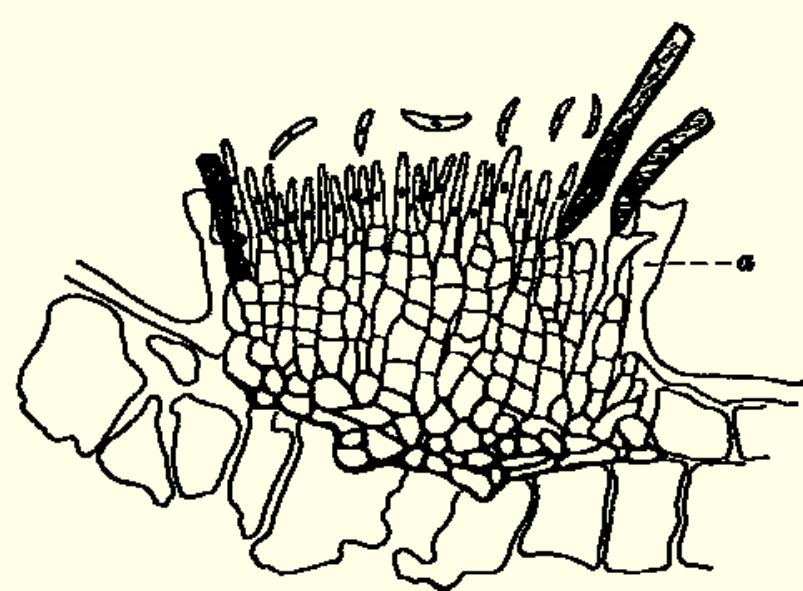

Slika 3: Prečni prerez zrelega acervula glive Colletotrichum trichellum. Povrhnjico lista je predrla seta (sterilna hifa $\mathrm{z}$ odebeljeno steno, ki štrli iz trosovnice), trosonosci nosijo konidije (Risba: Duke MM, 1928 v Buller, 1958)

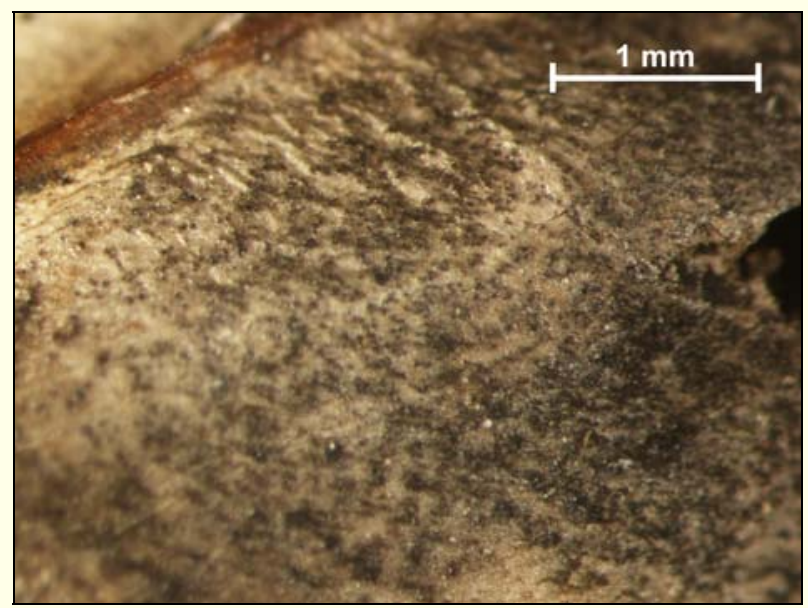

Slika 5: Konidiofori in konidiji glive Alternaria hederae makroskopsko (Foto: N. Ogris)

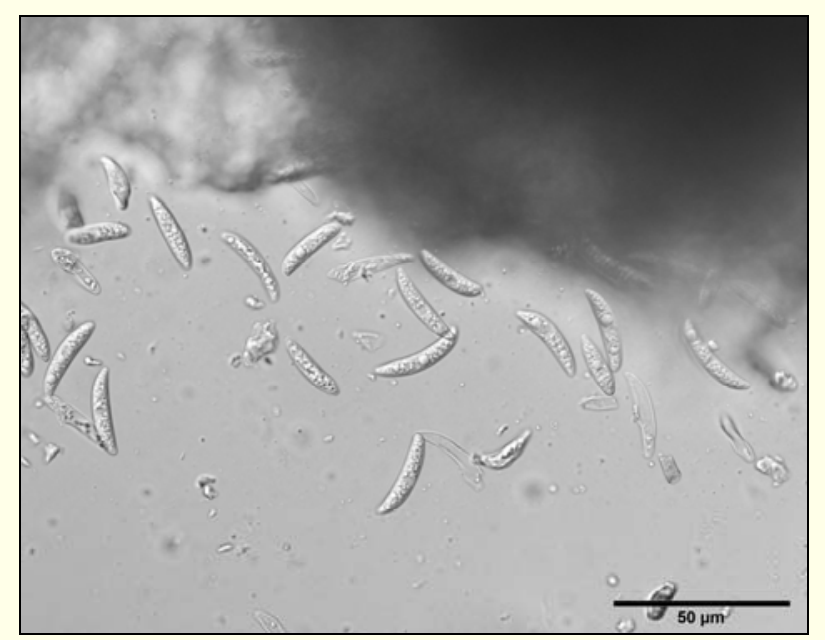

Slika 4: Konidiji glive Colletotrichum trichellum (Foto: $\mathrm{N}$ Ogris)

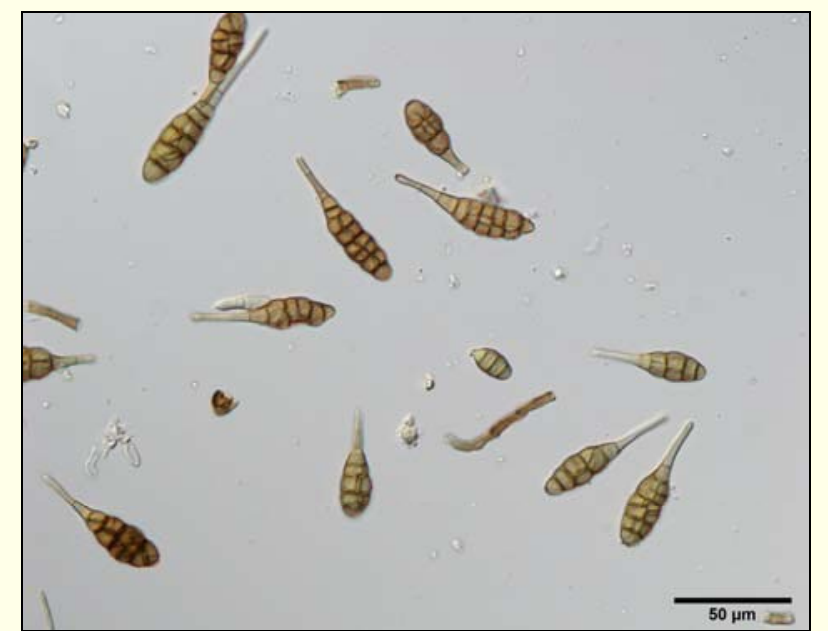

Slika 6: Konidiji glive Alternaria hederae mikroskopsko (Foto: N. Ogris) 